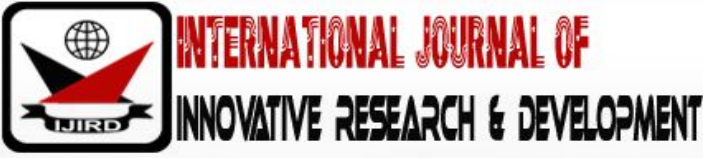

ISSN 2278 - 0211 (Online)

\section{Interstitial Artifactuality: Inventing New Realisms through the Conceptual Hybridization of Art, Design, Genres and Media}

\author{
Dr. Clement Emeka Akpang \\ Faculty of Environmental Sciences, Department of Visual Arts and Technology, \\ Cross River University of Technology, Nigeria
}

\begin{abstract}
:
Contemporary art is characterised by complexities and innovativeness, as artists continue to interrogate genre boundaries, creating new epistemologies and hybrid art that exists in-between and outside the parameters of established genres. This paper analysed the use of art in 'INTERSTICE 2016', to interrogate the intersections between primitivism and modernity; aesthetic appeal and repulsion, crafted forms and the readymade; detritus objects and the treasured; art and design; two dimension and three dimension; as well as the boundaries between femininity and power, as a critical framework for redefining/destabilizing established aesthetic constructs. Using discourse analysis and artistic methodology, the themes, materiality, styles and curating of the works on display, were subjected to an in-depth analysis. The paper concludes that the interrogation of intervening spaces between varying aesthetic idioms and genres, results in the creation of new approaches to realism that deconstruct ideological and cultural subjectivities and instigate new dialogues across periods and genres.
\end{abstract}

Keywords: Interstitial art, new realisms, artifactuality, contemporary, hybridity, in-between

\section{Introduction}

In his widely read book 'Relational Aesthetics' Nicolas Bourriaud argues that art develops and evolves according to periods and social context and "is not an immutable essence" (Bourriaud 2002: 11). This quality of art to evolve, he posits, creates a complex creative framework for blurring boundaries and intersecting various periods, cultures and genres through the conscious re-contextualization of aesthetic idioms and cultural idioms in new social contexts by different artists/ designers. Contemporary art is defined by such complex dynamism, which has resulted in the creation of new epistemologies and plethora of astounding/ compelling art genres since the decline of postmodernism. Contemporary art is defined by Tate Modern as 'art of the present day and relatively recent past of an innovatory or avant-garde nature' (Tate Modern 2010), and this definition points to why it is difficult to ascertain the exact timeframe when the phenomenon actually began. However, one this that is free of ambiguity is the fact that the complex ideas, stylistic configurations, and innovative genres of contemporary artistic expressionism, makes contemporary art aesthetically, intellectually, socially, politically and culturally engaging/ challenging hence the complex discourses it has instigated.

The complex, experimental and inventive approaches with which contemporary artists address conditions of contemporaneity, has resulted in the creation of new art formalisms that defy categorisation. This is because, the rapid flow of traffic, ideas, cultural exchange accelerated by the force of globalism in contemporary society has led to the abandoning of established aesthetic constructs, to embrace new inventions and cultural/aesthetic hybridism. It is this paradigm of hybridization and deterritorialization of cultures in contemporary society that is as Nikos Papastergiadis observes, compelling artists, designers and intellectuals to rethink their methods, and to invent new creative vocabularies in art (Papastergiadis 2005: 1). The results of this creative rethink are complex forms of representation involving the incorporation of images and aesthetic idioms from different cultures/locations/periods to create new innovative multiple visual codes. This defining feature of contemporary expressionism involving the actualization of artifactuality based on the concepts of appropriation, hybridism and intersections of styles, genres and media is of prime interest to this study. According to Perry and Wood, the crux of contemporary art revolves around the intersection of the past and present, traditional and contemporary, as well as juxtaposition of art, science and technology to capture contemporary society/ culture (Perry \& Wood 2006). Contemporary artists engage in complex intersections and re-contextualization of elements of traditionalism, modernist avant-gardism and contemporary culture as well as juxtaposition of 2D, 3D, painting, sculpture, graphics, textile, light installation etc., in art production to challenge genre exclusivity and deconstruct established notions of art. This new creative ethos results in the invention of art that exist in-between genres and cultures as convoluted yet fascinating creative spectacles that capture the 
conditions of contemporaneity "discerning the antinomies of the world as it is, display the workings of globality and locality, and imagine ways to represent and live ethically within them" (Smith 2006: 698). This intersectional approach to art/ design production is a creative adaptation by artists and designers to address the complexities of contemporaneity, globalism and universalism, especially its impact on their immediate societies. This intersection and transgression of genres in art production, frees contemporary artists and designers from the constraints of established conventions, giving them freedom to achieve the full potentialities of artistic expressionism in contemporary art-space. This creation of art that exists in-between established aesthetic/ genre constructs thus constitutes new approaches to realisms and art in general as exemplified in the complex works/ practices of renowned contemporary artists such as, Ai Weiwei, Banksy, Nakahiro Hiroyuki, Pablo Reinoso, Nnenna Okore and others, whose works deconstruct the boundaries between genres, cultures, periods, ideas and media.

The exhibition 'INTERSTICE 2016' at the University of Bedfordshire's School of Art \& Design, captured and proselytised this new conceptual/ methodological ethos to contemporary artistic expressionism. The exhibition took a critical and philosophical look at how art can be used to interrogate the intersections and in-betweens of concepts, genres and ideas; it interrogated the boundaries between primitivism and modernity; aesthetic appeal and repulsion, crafted forms and the readymade; detritus objects and the treasured, as well as the boundaries between feminine beauty and power in African context. By exploring the interstices and tensions that exist between these concepts, the artist created new epistemologies, and developed unique realisms and subjective parameters for 'artifactuality'. This paper critically reviews the works on display in 'INTERSTICE 2016', interrogating the projection of interstitial art that exists in-between established genres as the new context of contemporary art. Adopting discourse analysis and artistic methodology that provide for in-depth deconstruction of art objects, it places emphasis on in-depth analysis of the visual configurations and formalisms of varying artworks, to deconstruct the ideological implications of aesthetic/ conceptual hybridization/ intersection in contemporary artspace and how this new creative ethos challenges or re-define preconceived notions of art and design. The paper is divided into two main sections; following the introduction is a detailed analysis of the styles, themes and display (curating) of the works in the exhibition. It then proceeds to analyse the aesthetic and ideological implications of interrogating the interstices of various art genres as conceptual framework for re-inventing contemporary art's expression and reception.

\section{INTETSTICE 2016 - Styles, Themes and Curating}

On entering the gallery, viewers are confronted with the striking intersection of varying styles and aesthetic idioms that perfectly encapsulate the concept of the exhibition. The works on display are defined by a conscious triangulation of styles; three stylistic formalisms are prominent: realism, abstractionism and stylization all combined in the creation of art forms that blur and transgress genre boundaries. The pieces '1908i \& 1908ii 2016' (Figure 1) are large compositions created using the convention of realism. These two pieces reconstruct the historic confrontation in 1908 between colonial armed officers and women protesters revolting against British imposed taxation at Ijebu Ode. Through the medium of ink drawing and screen-printing, these large compositions reconstruct the battle scene capturing fine details of facial expressions, draperies and the chaotic charging movements of the rioting women advancing towards the British colonial regiment. Through masterful application of chiaroscuro the pieces captures the stern pose of the armed colonial officers and the charging war march of the nude women holding tree branches and chanting war songs. The accurate depiction of proportions, perspectives, and anatomical details, creates realistic pictures of that symbolic historic point in Nigeria's decolonization battles of which there exists no visual documentation till date. The ethos of realism is also adopted in the piece 'Price of Modernity 2015' (figure 2). The installation combines realistic formalism with the readymade; it is composed of a deconstructed male figure depicting truth-to-likeness (in his face and hands), submerged in a sea of three thousand shopping receipts. The installation exemplifies an interstitial art form that exist in-between art and the readymade to challenge our perceptions of what constitutes art. On the other hand, the installation 'Excessive Individualism 2014-2016' (figure 3) is created using the language of stylization, which combines realism and abstraction. The piece comprises of 759 lizards of different sizes and colours realistically sculpted from wood, discarded objects and resin, all crawling in one direction towards a giant male figure, created through the combination of realism and cubist abstractionism. Nonfigurative abstract expressionism is also a dominant visual idiom in the exhibition; the installation 'Haze 2016i' and the piece 'Haze 2016ii' (figure 4), are convoluted abstract formalisms created through the complex assemblage of varying sculpted wood/plaster compositions or forms, to capture the ambiguity of postcolonial African culture, identity and civilization. Each component of these installations is inscribed with distinct African ideographs combined into leitmotifs and patterns for surface finish on wood/plaster. Other works such as 'Reinterpretation I ii iii 2015 - 2016' (figure 5) are created through appropriation and assemblage. These large relief sculptural panels are constructed by appropriating and re-contextualizing discarded wood; each wood panel is inscribed with pattern-like decorations developed from indigenous African ideographs and symbols, then assembled together to create complex homogenous sculptural forms (relief panels). This creative ethos of assemblage is also manifest in the installation 'Clusters 2016' (figure 6). The installation is a complex composition of ten thousand matchsticks (readymade) of different colours assembled to represent the different continents of the world and the residence of people by colour to critique the idealised political concept of globalism.

The materials used in the creation of the works are multifaceted including wood, plaster, paper, fabric, canvas, and assorted found objects (old mattress, metal, wires and plastic). The artists drew upon this vast array of materials to also deploy materiality as a medium for interrogating the concept of interstice in contemporary art/ design. The juxtaposition of sculpted wood with finely designed satin fabric in 'Reinterpretation III 2016' and the combination of resin, plaster, discarded 
clothes, mattress and plastics in the installation 'Excessive Individualism 2016', capture the artist's complex manipulation/intersection of different materials to transgress genres boundaries in order to create art that exist in-between as new forms of realisms. The curating of the exhibition is systematically planned to influence viewers' experience of the gallery space by creating walk-paths in-between artworks defined by different genre parameters. The works are displayed according to themes and concepts - the three large installations that provide social commentary on contemporary society and designed to be viewed above eye level are installed in the central space of the gallery on the floor. The top floor section of the gallery is occupied by another large installation 'Haze 2016 I', which then leads to the piece 'Haze 2016 II', this convoluted construction piece then leads the viewers to the wall panels. In the display of the works, style is also carefully considered; realistic works are altered by or placed beside completely abstract forms or those that intersect realism and abstraction. On entering the gallery one is confronted with two large realistic screen-prints which explore the interstice between nudity/ beauty and power deployed in the battle against colonialism in 1908 in the Southern Protectorate of Nigeria; these realistic compositions are flanked by a large abstract installation of assembled wood constructions, and then followed by artworks that combine realism and the readymade. This systemic intersection of styles/ genres in the display of these artworks fits into the ambit of the narratives of interstitial art fostered by the artist especially the advocacy for blurring genre boundaries as the new ethos that will instigate the creation of new/ innovative approaches to art/ design expressionism in contemporary art-space. All works on display are boldly numbered to match the corresponding numbers and brief textual narratives in the catalogue provided to stir viewer's engagement, contemplation and meaning making/ extension.

It is this use of hybrid aesthetics, materiality and systemic display to interrogate the intersections and in-betweens of varying genres and concepts as a framework for inventing new approaches to realisms and redefining art proselytised in the exhibition 'INTERSTICE 2016' that is the crux of this paper. The works on display demonstrate how visual configurations of artefacts are conceptually manipulated to instigate new dialogues across periods, art genres and cultures, as well as draw attention to societal discourses especially the challenges of modern existence, and offer a new kind of gaze on narratives and spectacle of art/ design, globalism and excessive individualism in postcolonial Africa, all aimed at challenging established aesthetic constructs and cultural subjectivities.

\section{Aesthetic/ Ideological Implications of Exploring the Interstices of Art Genres}

The exhibition exemplified the use of art as a critical research tool for contextual/ideological/philosophical analysis. The convoluted juxtaposition of styles, materiality and systemic display of artefacts in 'INTERSTICE 2016', espoused varying critical conceptual/ theoretical stand points because the works on display emerged as visual documentations of intense primary and secondary research, with findings inscribed in forms and disseminated in a gallery setting. The artist used his works to elucidate varying contemporary views on artifactuality/ culture and contemporaneity by intersecting different art genres, concepts and materials to redefine contemporary art/ discourse and challenge preconceive artistic subjectivities. His works achieve this by,

\subsection{Destabilizing Established Aesthetic Constructs}

In this exhibition, art was used to critically and philosophically interrogate the intersections and in-betweens of genres, ideas and concepts, thereby dissolving genre boundaries and destabilizing established aesthetic constructs. One of the central ideas of the artist's interstitial approach to art-making is the interrogation of the interstices of genres and periods as conceptual/ideological framework for inventing new realisms and creating new epistemologies to challenge well-known notions about art and design in contemporary context. This ideology is proselytised visually through his complex combination of genres and styles in almost all artworks displayed in the gallery. 'Reinterpretation III 2016' (see figure 5) for example juxtaposes wood assemblage sculpture with satin fabric designed with African ideographs, draped across to link the split sculptural forms. This combination of two genres of art (sculpture and textile) to create a single piece, results in a new genre of art that is neither a sculpture nor a piece of textile design but exist in-between as 'Sculpture-textile'. The installation 'Price of Modernity 2015' (see figure 2) also adopts this critical approach to art. It is a convoluted composition that juxtaposes two aesthetic constructs - realistic sculpture and the readymade. The combination of the established aesthetic construct of modelling and casting with the ephemerality of the readymade (shopping receipts) in this installation, creates a new visual idiom that falls outside the ambits of traditional or established aesthetics, thus capturing perfectly the complexity and dynamism of contemporary expressionism.

This intersection of different aesthetic constructs challenges and blurs genre/ style boundaries. By creating artefacts not defined by the aesthetic parameters of a particular genre, the artist's works bridge the gaps between art genres, thus destabilizing their aesthetic constructs. These new art forms that exist in-between established styles, creates a new aesthetic dialogue, which challenges preconceived perceptions of art and design, by posing poignant questions about the definition/ context of art in contemporary art-space. It also proves the limitless artistic possibilities that lie in-between aesthetic constructs hitherto supressed by genre restrictions. Since contemporary art is still an evolving phenomenon, the interstitial aesthetics proselytised in this exhibition, demonstrate that art/ design genres are yet to be fully explored; for example, the combination of wood sculptures with textile fabric design, sculpted forms with readymade, screen-printing with oil painting etc., in these works, leads to new uncategorised genres such as 'Sculpture-textile', 'Print-painting' and 'Readymade-craft' etc., that all expand the definition and context of contemporary art/ discourse. These new interstitial art forms and artistic languages deconstruct established aesthetics and contribute to debates that argue against the categorization 
of contemporary art based strictly on established genre parameters, which only impede understanding and appreciation of the diverse dynamic formalisms that define contemporary art/ design.

\subsection{Deconstructing Ideological and Cultural Subjectivities}

The interrogation of the interstice between ideas, concepts, genres and media in this exhibition, deconstructs ideological and cultural subjectivities. By intersecting and hybridizing various art genres and visual idioms, the artist's works challenge long held perceptions about art, design and aesthetics. Firstly it challenged the categorisation of primitivism/traditionalism and contemporaneity in art. The large piece 'New Realism 2016' (figure 7) composed of seven separate large print designs juxtaposed into one homogenous print-art, is a unique intersection of periods and visual idioms in contemporary art. This piece is created through the appropriation, re-contextualization and reinventing of primitive/ traditional African ideographs and symbols used in pre-modern society as marks of tribal/ community identification, into contemporary art. Traditional African ideographs of Insibidi, Uli and Adinkra are composed and recomposed into a plethora of leitmotifs, then using African colour scheme of earth colours, each composition is further explored with colour and once the desired visual effects is reached, the compositions are repeated into patterns for large scale prints. The pre-modern associations of these appropriated ideographs with traditional body/wall paintings and religion often result in their classification as primitive, but this piece provides a new artistic dialogue by re-contextualizing such supposed primitive ideographs into contemporary print designs, thereby altering their context, and ascribing on them new meanings, forms, and reception as new realisms. This piece (New Realism 2016) represents a complex intersection of periods - it exist in-between traditionalism and contemporaneity as both print art, digital art and painting; thus it challenges and deconstructs what we consider primitive and that which we canonise as modern/contemporary. The contemporary re-invention and recontextualization of pre-modern African graphic systems, bridges in artistic sense the gap between pre-modern and contemporary periods, and reflecting the theory of relational aesthetic in contemporary art.

The installation 'Haze I 2016', and the relief sculptural panels 'Reinterpretation (I II III) 2015-2016' all constructed through the appropriation and 'upcycling' of discarded wood, challenges our perceptions of what we typify as rubbish/ trash and art/treasured objects. The dislocation of these discarded wood boards from trash bins, and their transformation into contemporary art forms, alters their context and meaning thus questioning our definition of art and trash. The conferment of art-hood on an object is often based on conceptual, ideological, contextual and cultural interpretations/ subjectivities; through the appropriation and re-contextualization of discarded wood (scaffolding boards) in these sculptures, the orthodoxy of the forms are challenged and re-interpreted with new aesthetic meanings. The new forms inscribed with stylised patterns, and flanked by the rot of old wood and displayed in a gallery, forces their reception as contemporary art rather that trash. The recontextualization of these detritus objects into contemporary sculptural forms thus deconstructs those ideological, aesthetic and cultural subjectivities, which interpret and confer artifactuality on select objects.

The large canvas pieces '1908 I, and II' explore the interstices between feminine nudity and power in African context. Indigenous battles for decolonization in Nigeria assumed various dimensions and although women provided the earliest forms of resistances by deploying the weaponry of nudity to resist imposed colonial taxation, (like the Ijebu Ode women revolt of 1908); their efforts are scantily documented or celebrated. In pre-independence Nigerian communities, feminine nudity represented absolute power, as women were considered central to the continuance and shaping of humanity in African cosmology. In 1908 nudity, beauty, and mass theatre coalesced into a cataclysmic force of resistance fostering indigenous battles against colonialism. The spectacle was compelling, as that which defines ideal womanly beauty in Africa and nourishes humanity (voluptuous breast, and bottom), became weapons for the defence of indigenous communities against the onslaught of imperialism. The dismantling of imperial military imposition as depicted in these pieces by the flaunting of feminine endowment in colonial Nigeria captures the powerful force of nudity/ beauty colonial Nigeria, which to a large extends still influences many contemporary societies. This piece instigates dialogues that interrogates and deconstruct cultural subjectivities regarding nudity and power; while the display of female endowment in one context constitutes a celebration of the self and beauty, in the pre-modern African context it represented the display of absolute unchallenged power while to some cultures, the display of nudity is rebuked as demeaning the female visage.

\subsection{Instigating New Dialogues on Societal Discourses}

The exhibition also demonstrated the use of interstitial art as a mechanism for socio-political commentary to instigate new dialogues across periods, draw attention to societal discourses especially the challenges of modern existence, and offer a new kind of gaze on narratives and spectacles of globalism and excessive individualism in postcolonial Africa. As Stiles and Selz (1995) opine, contemporary art engages directly with the conditions of contemporaneity as artists draw inspirations from seeing/ finding themselves permanently merged with life and engaged in the task of grasping the movements/ vitality before them that is simultaneously historical and contemporary (Stiles \& Selz 1996: 205). 'INTERSTICE 2016', captured this feature of critical artistic engagement with society through innovative art to interrogate the rapid transformations and cultural hybridization that defines contemporaneity. The appropriation of discarded objects, and the juxtaposition of art form with readymade in some of the artworks on display; provide commentaries on the travails of contemporary existence and society. One such contemporary problematic addressed in the artist's works is the phenomenon of Excessive Individualism. By excessive individualism I refer to a condition in postcolonial Africa were select individuals gain power through rigged systems, monopolize their nation's wealth and colonize their own people under democratic-dictatorship funded by widespread 
corruption. According to Samba Diop, "The force labour of capitalism and bureaucratic class nurtured during the colonial era was promoted as the new instrument of exploitation in the era of neocolonialism...this was the genesis of Africa's comprador bourgeoisie whose function is to facilitate the continuing exploitation of Africa's resources" (Diop 2012: 197); while Ekeh observes that This bourgeois groups influenced colonial Africa and continue to influence post-colonial African politics operating ideologies routed in colonial thinking as weapons and mechanism for legitimating their hold on their own people (Eke 1975). The installation 'Excessive Individualism 2016' through the combination of abstractionism and realism and use of materiality/ exaggeration as visual metaphors exposes this adverse phenomenon. The piece comprises of a large scale male stylized figure created with refined materials to capture the extravagance of the bourgeois dictatorial political class in Africa looking down on the subdued masses represented as lizards sculpted with discarded detritus objects crawling on their bellies towards the male dominant figure, representing their oppression, penury and subjugation by corrupt dictatorial politicians who have grown above their countries.

Another piece that instigates new social dialogue is the 'Price of Modernity 2015', which juxtaposes three thousand shopping receipts (readymade) with a sculpted human figure drowning in the bills to comment on the constraints of contemporaneity and the enslavement of modern man by the cost of modern existence. In an increasingly industrialised, digitised and materialised world, man's identity, persona, and power are determined only by his financial wherewithal; thus the installation draws attention to the adverse struggles to attain wealth in contemporary society which defines one's actions and thought processes as money has become the password to modern living and without it, one ceases to experience/ enjoy the bliss of modern life. The visual configuration of the installation projects unto the viewer poignant visual cues that resonate with the overwhelming pressures and exhaustions of societal demands as people continue to drown in pools of contemporary economic uncertainties and travails. Finally, the installation 'Clusters 2015' provide a new gaze on the falsity of globalism and universality. The appropriation and re-contextualization of matchsticks in this piece is symbolic; within its formal and colour configuration lies the critical exposure of the ambiguity and hypocrisy of the concept of globalism which is an idealised political construct that doesn't exist beyond its theoretical context. This installation problematizes universalism and globalism and draws attention to the fact that, race, colour and religious orientations still determine people's locations in different parts of the world. The installation constitutes of ten thousand assorted matchsticks installed in well-defined colour schemes to represent the various continents of the world; light brown for Europe; dark brown, yellow and red for Asia; black for Africa; light brown for Australia; green for South America; light brown and blue for North America etc. The dominant matchstick colour(s) representing each continent is then punctuated with small clusters of other colours to represent peoples from other continents (immigrants); these small clusters of migrant groups are installed within the host continents/ cultures in such a way that they do not blend within the larger context but are confined in constrained communities. This demonstrates that race, colour and religion still constitutes the parameters for peoples acceptability or discrimination in different parts of the world, hence exposing the supposed global connectivity, universalism and free movement purported in the doctrine of globalism a political hoax. This installation (Clusters 2016) is a visual critique of veiled racism and discrimination still inscribed in the cultural fabric of many nations, which are often coated, with cosmetic display of humanitarianism by globalist politicians. In this sense, the installation using visual configuration as a starting point instigate new dialogue on the idealised concept of globalism by offering an alternative subversive gaze untainted by global political correctness.

\section{Conclusion}

This paper interrogated the conceptual/ ideology constructs of the works on display in 'INTERSTICE 2016'. The artists' creation of art through the appropriation, intersection and hybridization of genres, media and aesthetic idioms led to the creation of new approaches to realisms (art formalisms) that exists in-between establish aesthetic constructs. The conceptual and ideological implications of this new ethos - that is the complex intersection of various genres, ideas, concepts and periods, is the invention of contemporary art that defies stylistic categorisation and that challenges viewer's preconceived notions on art and design. This paper thus concludes that, interstitial art constitutes the new framework of contemporary artistic expressionism that effectively captures the conditions of contemporaneity, and that appropriation, hybridization, and recontextualization are crucial in contemporary practice for actualizing the multifaceted potentialities of art/ design.

\section{References}

i. Bourriaud, N., Pleasance, S., Woods, F., \& Copeland, M. (2002) Relational Aesthetics. Dijon: Les presses du reel.

ii. Diop, S. (2012) 'African Elites and their Post-colonial Legacy: Cultural, Political and Economic Discontent-by Way of Literature', Africa Development, 37(4), pp. 221-235.

iii. Ekeh, P. P. (1975) 'Colonialism and the Two Publics in Africa: a Theoretical Statement', Comparative Studies in Society and History, 17(01), pp. 91-112.

iv. Papastergiadis, N. (2005) 'Hybridity and Ambivalence Places and Flows in Contemporary Art and Culture', Theory, Culture \& Society, 22(4), pp. 39-64.

v. Perry, G., \& Wood, P. (2004) Themes in Contemporary Art (Vol. 4). London: Yale University Press.

vi. Smith, T. (2006) 'Contemporary Art and Contemporaneity', Critical Inquiry (32) 4, pp. 681-707.

vii. Stiles, K., \& Selz, P. H. (1996) Theories and Documents of Contemporary Art: A Sourcebook of Artists' Writings (Vol. 35). California: University of California Press. 


\section{Appendix}
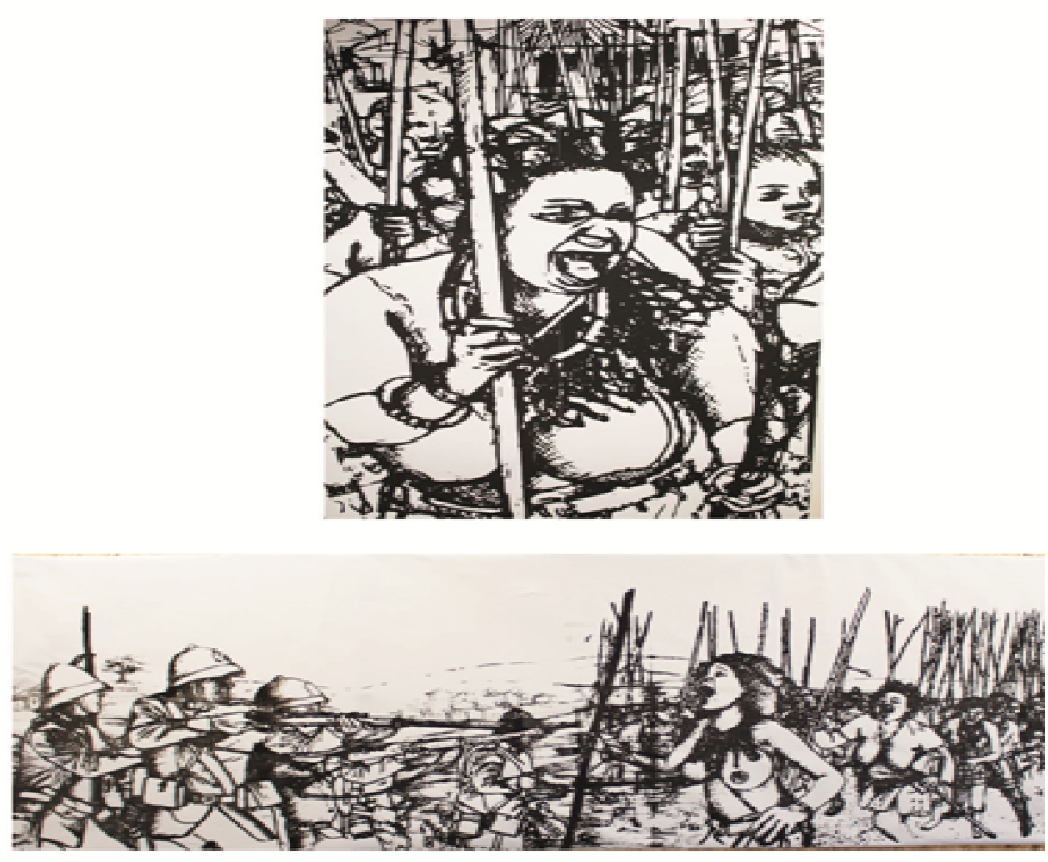

Figure 1: Clement Akpang - 1908i \& 1908ii 5x7ft, 14x3ft Ink on Canvass

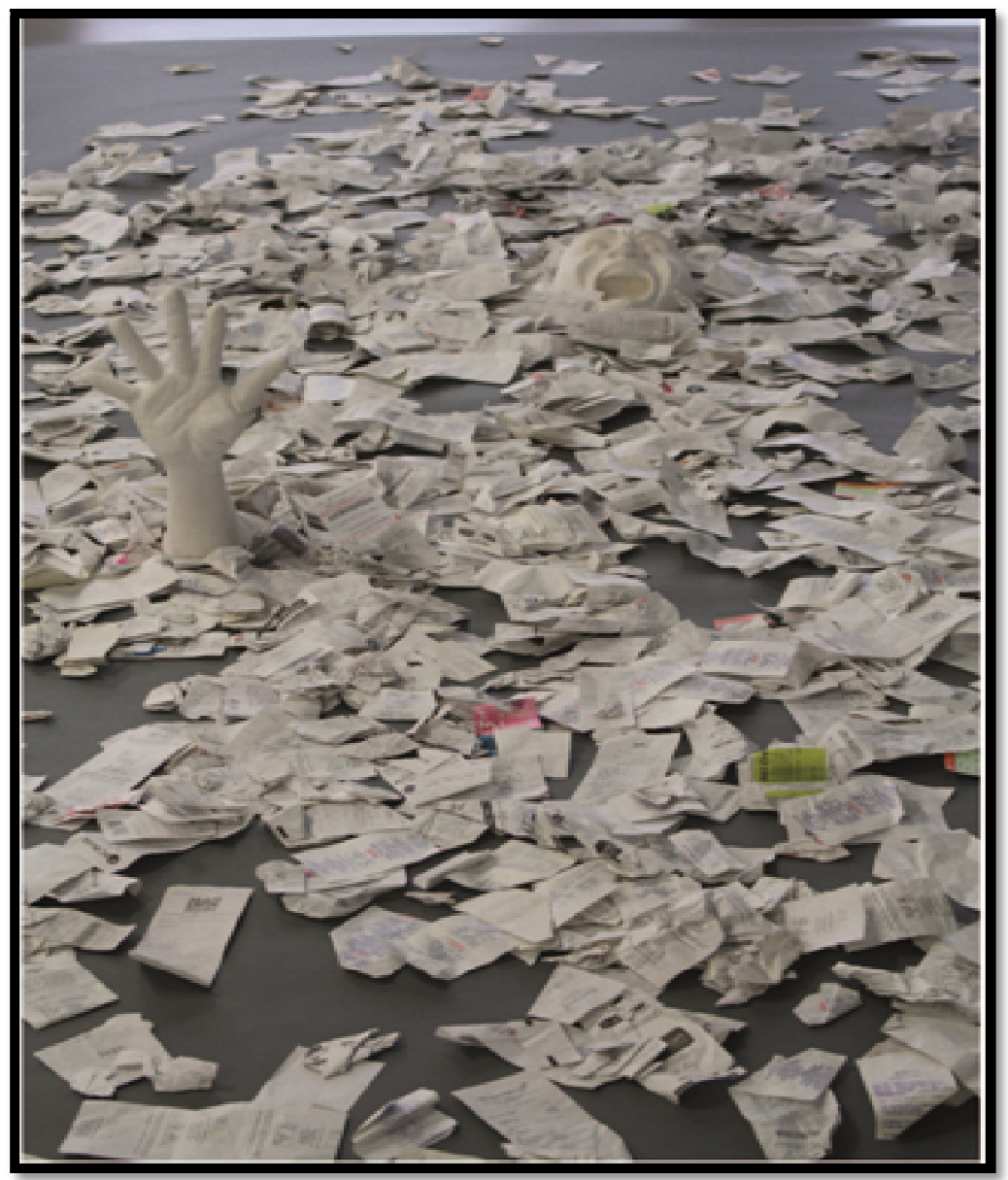

Figure 2: Clement Akpang - Price of Modernity 2016 19x7ft Discarded Receipts and Casting Plaster 


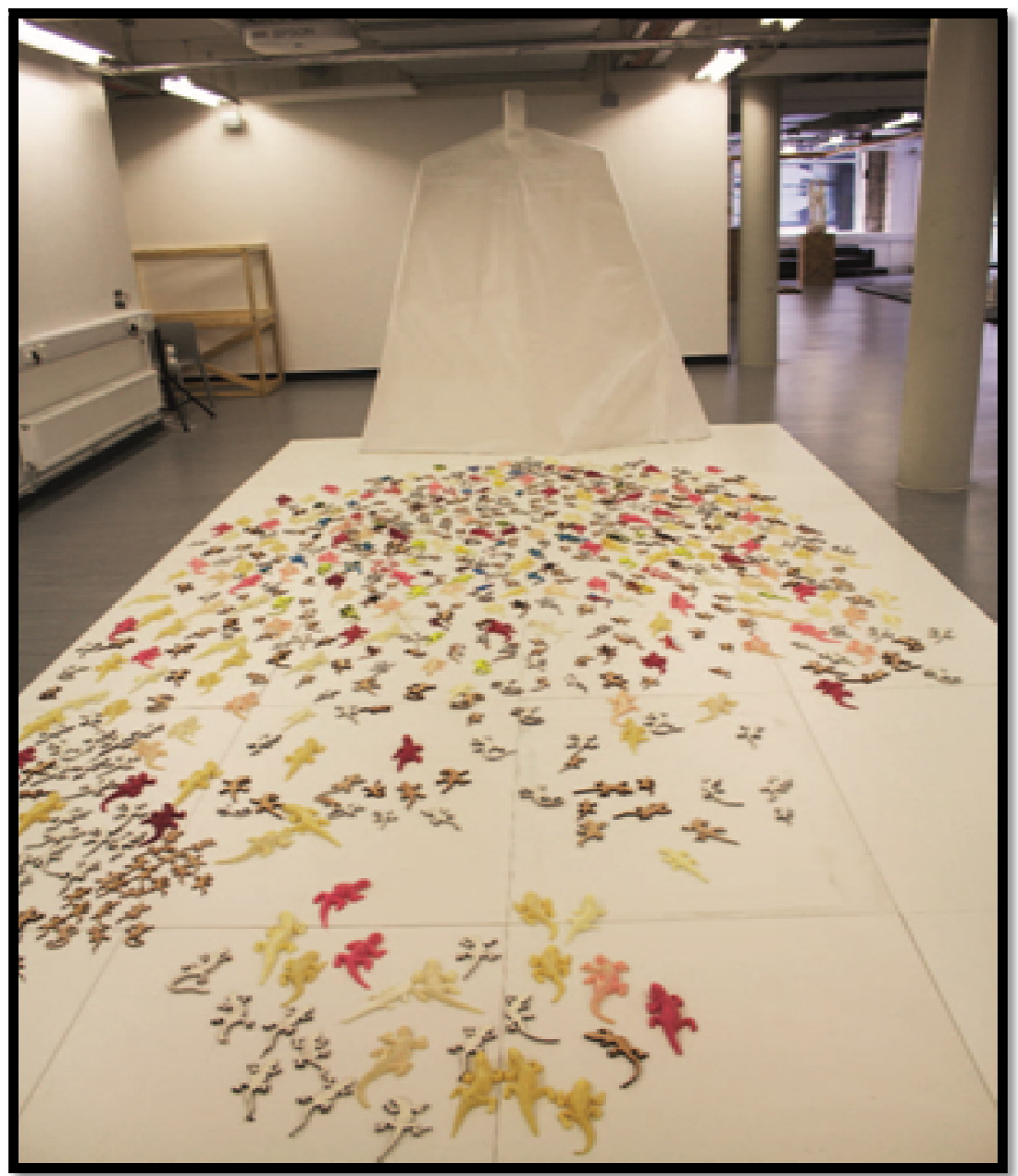

Figure 3: Clement Akpang - Excessive Individualism 2016 19x15ft Discarded Wood, Plastic, Resin and Canvass

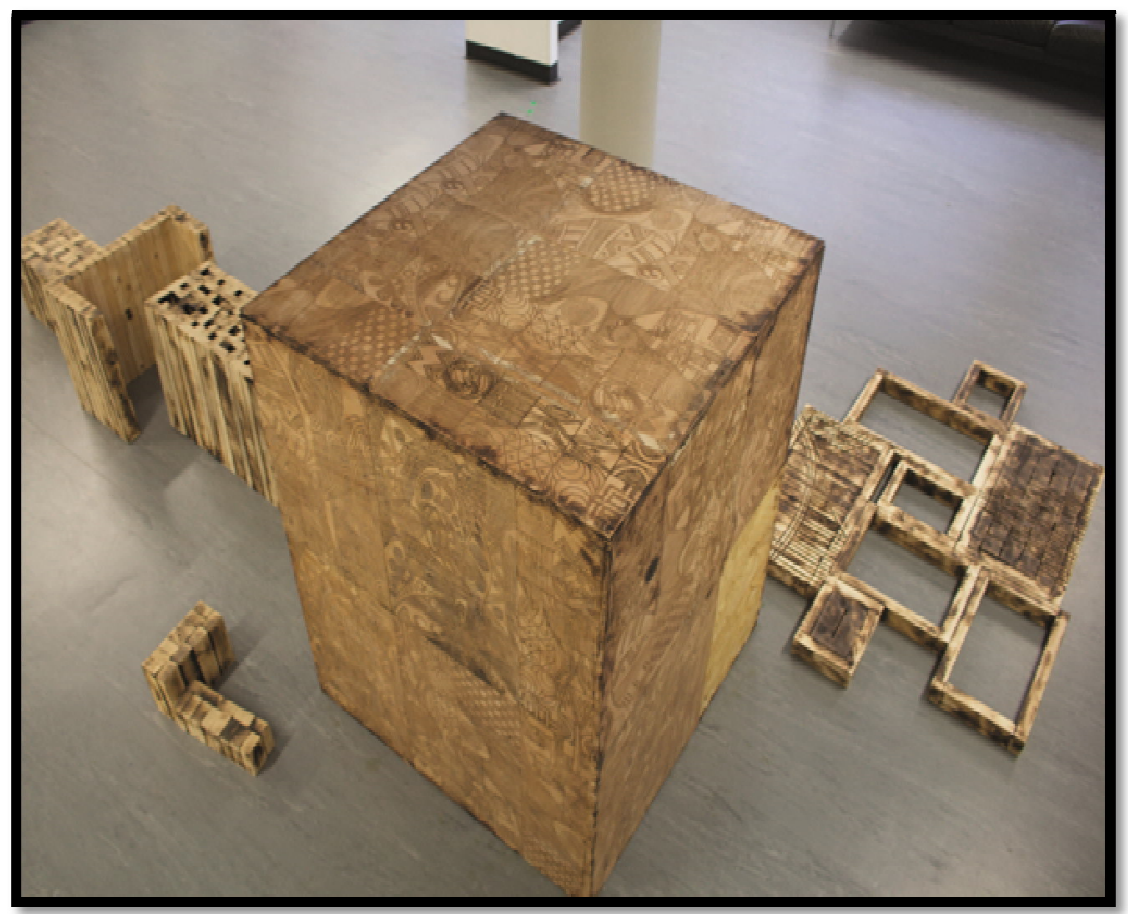

Figure 4: Clement Akpang - Haze Ii 2016 - 9x4ft - Discarded Wood 


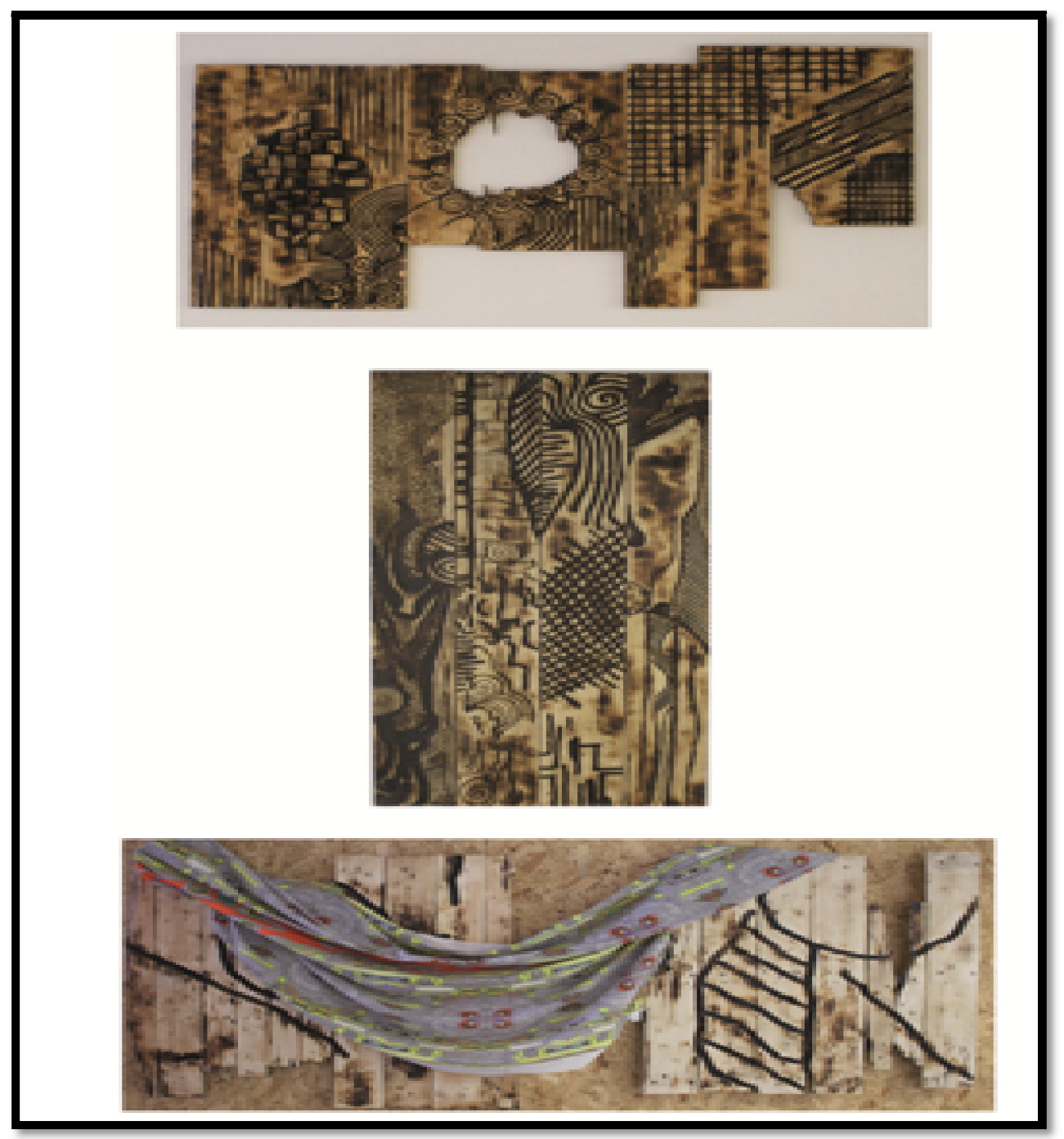

Figure 5: Clement Akpang - Reinterpretation I Ii Iii 2015 - 2016 - Discarded

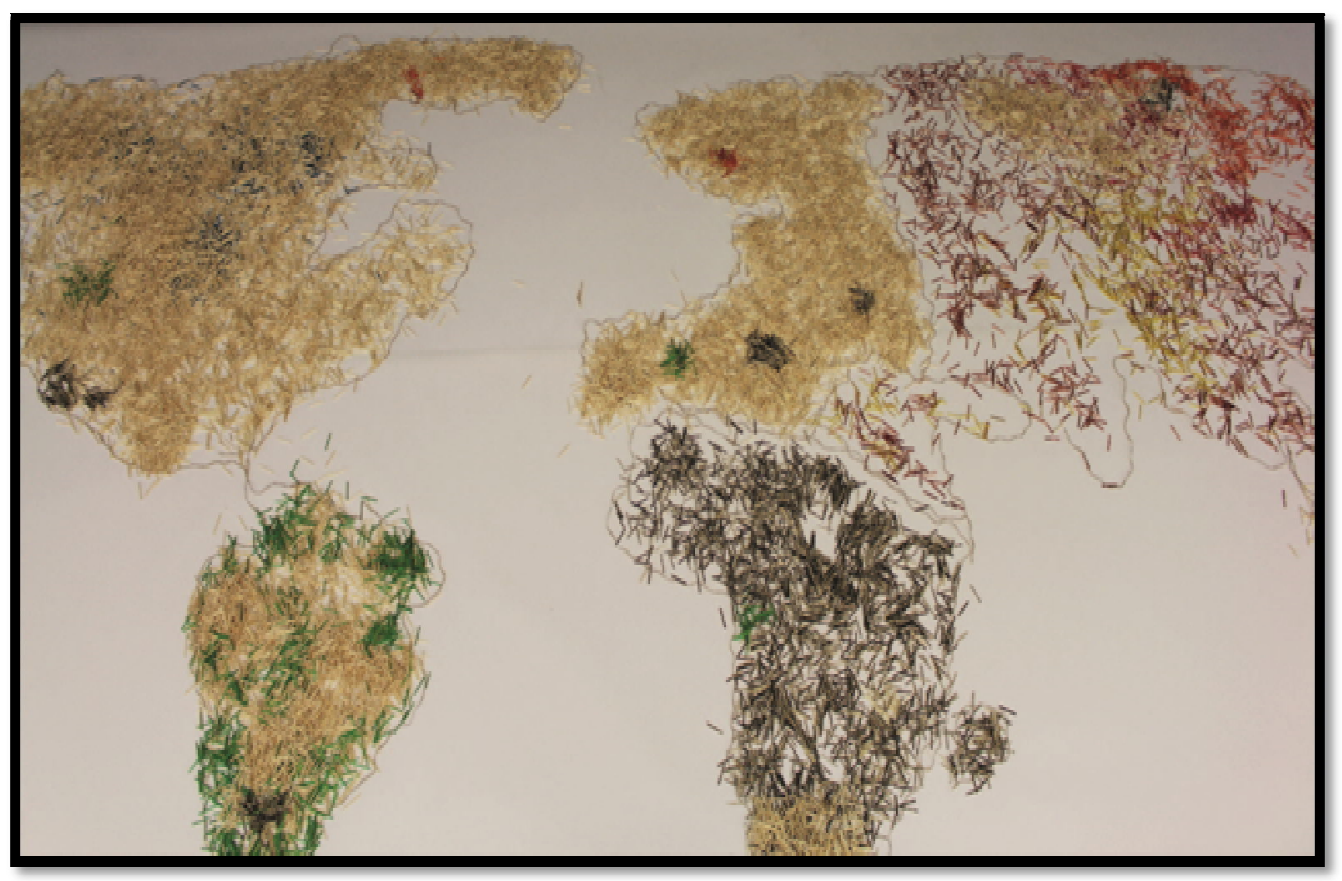

Figure 6: Clement Akpang - Clusters 2016 19x7ft - Matchsticks 


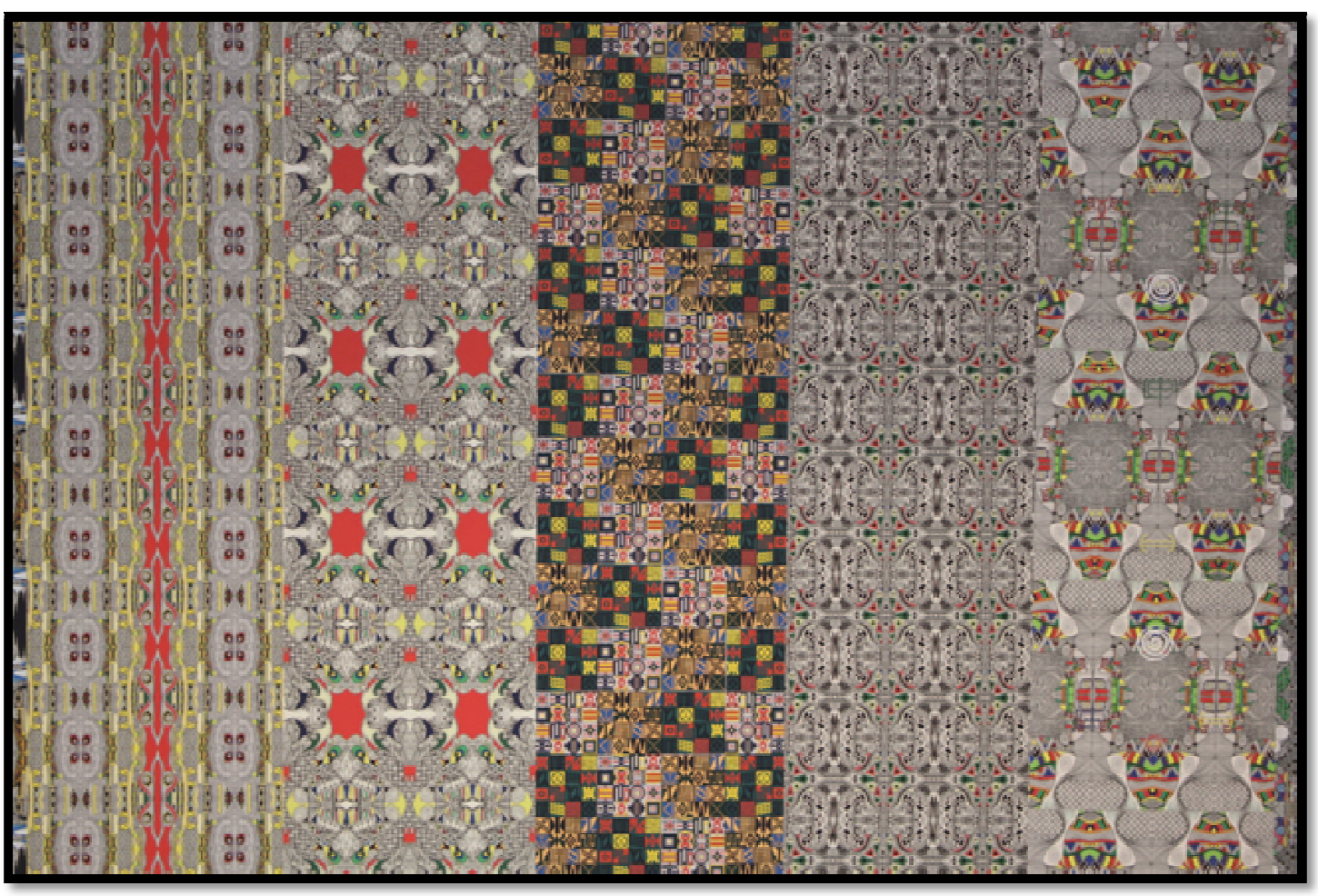

Figure 7: Clement Akpang - New Realism 2016’ 14x9ft - Ink on Paper 